\title{
Validity of the Handheld Expiratory Flowmeter for COPD Screening in the Primary Care Setting of China
}

\author{
Shuyun Chen ${ }^{1,2, *}$ \\ Xiaochen $\mathrm{Li}^{1,3, *}$ \\ Zihui Wangl,* \\ Yumin Zhou' \\ Dongxing Zhao (D) \\ Zhuxiang Zhao ${ }^{1,4}$ \\ Sha Liu' \\ Pixin Ran'
}

'State Key Laboratory of Respiratory Disease, Guangzhou Institute of Respiratory Diseases, National Clinical Research Center for Respiratory Disease Guangzhou, First Affiliated Hospital of Guangzhou Medical University, Guangzhou Medical University, Guangzhou, Guangdong Province, People's Republic of China; ${ }^{2}$ Department of Respiratory and Critical Care Medicine, First Affiliated Hospital of Nanchang University, Nanchang, Jiangxi Province, People's Republic of China; ${ }^{3}$ The People's Hospital of Hubei Province, Wuhan, Hubei Province, People's Republic of China; ${ }^{4}$ The First People's Hospital of Guangzhou City, Guangzhou, Guangdong Province, People's Republic of China

*These authors contributed equally to this work
Purpose: The use of simple and affordable screening tools for chronic obstructive pulmonary disease (COPD) is limited. We aimed to assess the validity of a handheld expiratory flowmeter (Vitalograph Ltd., COPD- $6^{\circledR}$, Ireland) for COPD screening in Chinese primary care settings.

Methods: In our cross-sectional study, subjects were randomly selected in eight primary care settings. Tests with the handheld expiratory flowmeter and the conventional spirometry were sequentially performed on all participants. The correlation between the handheld expiratory flowmeter and the conventional spirometry was determined. Validity was determined by the area under the receiver operator characteristic curve (AUC) of the forced expiratory volume in one second $\left(\mathrm{FEV}_{1}\right)$ forced expiratory volume in six seconds $\left(\mathrm{FEV}_{6}\right)$ that used to detect airway obstruction. The sensitivity, specificity, predictive values, and likelihood ratio were calculated according to different $\mathrm{FEV}_{1} / \mathrm{FEV}_{6}$ cut-off points.

Results: A total of 229 subjects (15.4\%) were diagnosed with airflow limitation by conventional spirometry. $\mathrm{FEV}_{1}, \mathrm{FEV}_{6}$, and $\mathrm{FEV}_{1} / \mathrm{FEV}_{6}$ measured by the handheld expiratory flowmeter were correlated with $\mathrm{FEV}_{1}, \mathrm{FVC}$, and $\mathrm{FEV}_{1} / \mathrm{FVC}$ measured by the conventional spirometry $\left(r=0.889,0.835\right.$ and $0.647, \mathrm{p}<0.001$ ), respectively. AUC of the $\mathrm{FEV}_{1} / \mathrm{FEV}_{6}$ to determine airflow obstruction was 0.857 ( $95 \%$ CI: 0.826 to 0.888 ). No significant difference of AUC was observed between the symptomatic group and the asymptomatic group ( $\mathrm{AUC}=0.869$ vs $0.843, \mathrm{P}=0.425$ ). A similar phenomenon was found in the AUC of smokers and never-smokers ( $\mathrm{AUC}=0.862$ vs $0.840 ; \mathrm{P}=0.515$ ). The cut-off point for $\mathrm{FEV}_{1} / \mathrm{FEV}_{6}$ was 0.77 and the corresponding sensitivity and specificity were $71.2 \%$ and $89.8 \%$, respectively. Conclusion: The handheld expiratory flowmeter might be used as a screening device for COPD in Chinese primary care settings.

Keywords: COPD screening, airflow limitation, $\mathrm{FEV}_{1}, \mathrm{FEV}_{6}$, lung function

\section{Introduction}

Characterized by persistent airflow limitation, chronic obstructive pulmonary disease (COPD) was a high-prevalence disease with heavy mortality and morbidity burden. ${ }^{1,2}$ It is reported that COPD caused $2.6 \%$ of global disability-adjusted life years (DALYs) and 3.2 million death worldwide in $2015 .^{3}$ Airflow limitation is defined as a post-bronchodilator forced expiratory volume in 1 second $\left(\mathrm{FEV}_{1}\right) /$ forced vital capacity $(\mathrm{FVC})<0.7$ and regarded as the essential test for the diagnosis of COPD. ${ }^{4}$ In COPD patients, persistent airflow limitation might lead to the substantially impaired quality of life and higher risk of premature death. ${ }^{5}$ 
For the long-term asymptomatic phase, countless COPD patients remained undiagnosed until the onset of severe symptom. ${ }^{6,7}$ Early symptoms of COPD are subtle and unrecognized for numbers of patients. The reduction of lung function is often substantial and irreversible when the patient is diagnosed for the first time. ${ }^{8}$ What is more, the reduction of lung function might lead to poor healthrelated quality of life. ${ }^{7-9}$ Although undiagnosed COPD patients usually have fewer exacerbations than severe COPD patients, they also require amount of medical care services for exacerbation events that should have been avoided. ${ }^{10}$ Therefore, misdiagnosis of COPD could also bring considerable health burden. In this context, early screening for COPD is regarded as a potential method to reduce the burden of morbidity and mortality of patients. ${ }^{7}$ However, the problem of underdiagnosis on COPD is obvious (ranging from $72 \%$ to $93 \%$ ). ${ }^{7}$ There were increasing interests in improving the early detection of COPD in the primary care setting during the last decade. Spirometry is a well-established tool for quantifying airflow limitation and the diagnosis of patients with COPD. ${ }^{5}$ However, there are several seasons for conventional spirometry in primary care practice. First, the expensive cost of the machine has limited technology extension. Second, shortness of professional training led to the unreliable quality of test and interpretation in primary care settings. ${ }^{11-14}$ The US Preventive Services Task Force and the American College of Physicians recommend that spirometry should not be used to screen for airflow limitation in individuals without respiratory symptoms. The use of conventional spirometry in primary care setting may result in a waste of medical resources and an overestimation of COPD burden. ${ }^{15,16}$

The use of simple and affordable screening tools is limited. Forced expiratory volume in 6 seconds $\left(\mathrm{FEV}_{6}\right)$, a easily achieved and reproducible measurement for portable spirometers, has been regarded as an alternative to FVC. ${ }^{17}$ Primary studies had found that $\mathrm{FEV}_{1} / \mathrm{FEV}_{6}$ could be used as a substitute for the $\mathrm{FEV}_{1} / \mathrm{FVC}$ in the diagnostic screening for COPD. ${ }^{18}$ There is a strong correlation between $\mathrm{FEV}_{1} / \mathrm{FVC}$ and $\mathrm{FEV}_{1} / \mathrm{FEV}_{6} \cdot{ }^{19-22}$ Consequently, inexpensive, user-friendly, and hand-held devices for measuring $\mathrm{FEV}_{1}$ and $\mathrm{FEV}_{6}$ have been produced to detect COPD in primary care. ${ }^{23-29}$

Vitalograph COPD- $6^{\circledR}$ (model number 4000, Vitalograph Ltd., Ireland) is one kind of emerging devices. Primary care physicians can obtain $\mathrm{FEV}_{1}$, $\mathrm{FEV}_{1} \%$ predicted, $\mathrm{FEV}_{6}, \mathrm{FEV}_{6} \%$ predicted, $\mathrm{FEV}_{1} /$
$\mathrm{FEV}_{6}$, and lung age by the handheld expiratory flowmeter. It can also provide the diagnosis of airflow limitation and severity classification according to the Global Initiative for Chronic Obstructive Lung Disease (GOLD) guideline. ${ }^{5}$ However, no study has examined the validity of the handheld expiratory flowmeter in low- or middle-income countries, including China. Furthermore, the best cut-off value used to define airflow limitation remains uncertain in China. Therefore, we designed this study to assess the validity of the handheld expiratory flowmeter for COPD screening in primary care settings in China.

\section{Methods}

\section{Setting}

With the socioeconomic differences between rural and urban regions, two urban streets and two rural communities were randomly selected from an urban region (Guangzhou, Guangdong Province) and a rural region (Lianping, Guangdong Province), respectively. Two primary care settings were selected from each of the street/ community mentioned above. Finally, eight primary care settings were involved in our study.

\section{Study Population}

The sample size of each age group was calculated according to the percentage of the population aged $\geq 40$ years reported in the latest census. In selected primary care settings, 200 residents from four different age groups $(40-49,50-59,60-69$, and $\geq 70)$ was required. Prior to enrollment, all participants signed informed consent documents for all the procedures.

There were several exclusion criteria for spirometry and the handheld expiratory flowmeter testing to avoid: 1) medical history of thoracic, abdominal or eye surgery in previous 3 months; 2) medical history of acute heart events (eg, angina, acute myocardial infarction, and malignant arrhythmia) in previous 3 months; 3) hospitalizations for heart diseases in the previous 1 month; 4) patients with active pulmonary tuberculosis disease or taking anti-tuberculosis drugs; 5) patients with a history of retinal detachment; 6) patients with new tumor diagnosed or undergoing a tumor treatment; 7) patients with cognitive impairment or mental disorder; 8) high paraplegia or thoracic deformity; and 9) women during pregnancy or lactation. 


\section{Data Collection}

\section{Procedures}

Unique ID number was assigned to each participant. A standardized questionnaire, handheld expiratory flowmeter testing, and conventional spirometry was conducted for each participant sequentially.

\section{Handheld Expiratory Flowmeter Testing}

Handheld expiratory flowmeter testing was executed by well-trained primary care physicians. At least three maneuvers were performed for each participant without the use of bronchodilator. Results should have met criteria for acceptability (forced expiration for at least $6 \mathrm{~s}$ ) and reproducibility (at least three acceptable flow-volume curves and the second-highest $\mathrm{FEV}_{6}$ and $\mathrm{FEV}_{1}$ were within $0.2 \mathrm{~L}$ or $10 \%$ of highest value). We selected the best value for the report.

\section{Spirometry}

Spirometry testing was performed independently by trained operators according to American Thoracic Society/European Respiratory Society guidelines. ${ }^{30}$ Operators were blinded to the test results of the handheld expiratory flowmeter. All study sites used the same model spirometer (JAEGER-Master Screen Pneumo ${ }^{\mathbb{R}}$, Carefusion $^{\text {TM }}$, GER). Spirometers were calibrated before each day's testing. Lung function parameters were measured before and 15-25 minutes after inhaling a dose of $400 \mu \mathrm{g}$ salbutamol through a $500-\mathrm{mL}$ spacer. We determined a quality grade (A-F) based on acceptable maneuvers and repeatability of the $\mathrm{FEV}_{1}$ and $\mathrm{FVC}^{31}{ }^{31}$ Spirometry results with grades $\mathrm{A}, \mathrm{B}$, or $\mathrm{C}$ were considered acceptable for analysis.

\section{Definitions and Diagnostic Criteria of COPD}

Conventional spirometry results were classified as COPD if the post-bronchodilation $\mathrm{FEV}_{1} / \mathrm{FVC}$ ratio was $<0.7$. COPD was classified as stage I $\left(\mathrm{FEV}_{1}>80 \%\right.$ of the predicted value), stage II $\left(50 \% \leq \mathrm{FEV}_{1}<80 \%\right.$ of the predicted value), stage III ( $30 \% \leq \mathrm{FEV}_{1}<50 \%$ of the predicted value), and stage IV ( $\mathrm{FEV}_{1}<30 \%$ of the predicted value).

\section{Analysis}

Standard validation measures, including sensitivity, specificity, positive predictive value (PPV), negative predictive value (NPV), and likelihood ratio (for a positive test, $\mathrm{LR}+$ ) were calculated at different cut-off points of $\mathrm{FEV}_{1} / \mathrm{FEV}_{6}$. ROC curve and Youden index (subtract 1 from the sum of sensitivity and specificity) were used to facilitate the cutoff point. The correlations of $\mathrm{FEV}_{1}, \mathrm{FEV}_{6}, \mathrm{FEV}_{1} / \mathrm{FEV}_{6}$ measured by the handheld expiratory flowmeter (prebronchodilator), with $\mathrm{FEV}_{1}, \mathrm{FVC}, \mathrm{FEV}_{1} / \mathrm{FVC}$ measured by spirometry (post-bronchodilator), were examined by Pearson's correlation analysis and Bland-Altman plots. ${ }^{27}$ The 95\% confidence interval was presented for all variables.

Our study protocol was approved by the Medical Ethics Committee of the Guangzhou Institute of Respiratory Diseases and conducted in accordance with the Declaration of Helsinki. Analysis was performed in SPSS (version 24), GraphPad PRISM (version 7) and MedCalc(v12.7).

\section{Results}

1650 subjects were initially recruited (978 from urban region, 672 from the rural county). We excluded 120 subjects because of missing data, and 43 subjects whose quality results of spirometry were under grade C. Information about symptoms was available from 1486 subjects. There were 845 (56.9\%) never-smokers and 641 (43.1\%) smokers in our study. The prevalence of COPD was different among diverse smoking status and respiratory symptoms population (Table 1). A total of 1258 (84.7\%) subjects with $\mathrm{FEV}_{1} / \mathrm{FVC} \geq 70 \%, 229$ (15.4\%) were diagnosed $\mathrm{COPD}\left(\mathrm{FEV}_{1} / \mathrm{FVC}<70 \%\right)$. A total of $105(45.9 \%)$ COPD patients were GOLD stage I, 91 (39.7\%) were GOLD stage II, 28 (12.2\%) were GOLD stage III, and $5(6.3 \%)$ were GOLD stage IV.

Figure 1A shows the strong correlation between $\mathrm{FEV}_{1}$ measured by two machines in total population $\left(r_{1}=0.889\right.$, $\mathrm{P}<0.001)$, non-COPD group $\left(r_{2}=0.869, \mathrm{P}<0.001\right)$ and COPD group $\left(r_{3}=0.907, \mathrm{P}<0.001\right)$. Significant difference was observed between non-COPD group and COPD group $(z=2.509, \mathrm{P}=0.012)$. Figure 1B shows strong relationships between $\mathrm{FEV}_{1}$ measured by the spirometry and the handheld expiratory flowmeter in groups of GOLD stage I $\left(r_{\mathrm{I}}=0.810\right.$, $\mathrm{P}<0.001)$, stage II $\left(r_{\text {II }}=0.802, \mathrm{P}<0.001\right)$ and stage III $(r$ ${ }_{\mathrm{III}}=0.637, \mathrm{P}<0.001$ ), but nonsignificant correlation was found in GOLD stage IV group $\left(r_{\mathrm{IV}}=0.844, \mathrm{P}=0.072\right)$. No statistical significance was found among GOLD stage I, stage II and stage III $\left(r_{\mathrm{I}}\right.$ vs $r_{\mathrm{II}}: z=0.141, \mathrm{P}=0.887 ; r_{\mathrm{I}}$ vs $r_{\mathrm{III}}$ : $z=1.675, \mathrm{P}=0.094 ; r_{\text {II }}$ vs $\left.r_{\text {III }}: z=1.558, \mathrm{P}=0.119\right)$. BlandAltman graph of $\mathrm{FEV}_{1}$ measured by the spirometry and the handheld expiratory flowmeter is shown in Figure 1C. 
Table I Characteristics of All Participants

\begin{tabular}{|c|c|c|}
\hline & $\begin{array}{l}\text { Non-COPD } \\
(\mathrm{N}=\mid \mathbf{2 5 8})\end{array}$ & $\begin{array}{l}\text { COPD } \\
(\mathrm{N}=229)\end{array}$ \\
\hline \multicolumn{3}{|l|}{ Area } \\
\hline Urban & 824 & 121 \\
\hline Rural & 434 & 108 \\
\hline \multicolumn{3}{|l|}{ Sex } \\
\hline Men & 689 & 188 \\
\hline Women & 569 & 41 \\
\hline \multicolumn{3}{|l|}{ Age (years) } \\
\hline $40-49$ & 215 & 7 \\
\hline $50-59$ & 568 & 73 \\
\hline $60-69$ & 372 & 92 \\
\hline$\geq 70$ & 103 & 57 \\
\hline \multicolumn{3}{|l|}{ BMI $\left(\mathbf{k g} / \mathbf{m}^{2}\right)$} \\
\hline$<18.5$ & 84 & 32 \\
\hline $18.5-23.9$ & 653 & 129 \\
\hline $24.0-27.9$ & 403 & 57 \\
\hline$\geq 28.0$ & 118 & 11 \\
\hline \multicolumn{3}{|l|}{ Smoking status } \\
\hline Never-smoker & 775 & 70 \\
\hline Smoker & 482 & 159 \\
\hline \multicolumn{3}{|c|}{ Respiratory symptoms } \\
\hline $\begin{array}{l}\text { With respiratory } \\
\text { symptom }\end{array}$ & 251 & 111 \\
\hline $\begin{array}{l}\text { Without respiratory } \\
\text { symptom }\end{array}$ & 1006 & 118 \\
\hline \multicolumn{3}{|l|}{ Lung function } \\
\hline $\mathrm{FEVI} / \mathrm{FVC}>0.7$ & 1258 & - \\
\hline GOLD stage I & - & 105 \\
\hline GOLD stage II & - & 91 \\
\hline GOLD stage III & - & 28 \\
\hline GOLD stage IV & - & 5 \\
\hline
\end{tabular}

The limit of Agreement (LoA) was 0.445 0.816 L, and $4.5 \%(67 / 1487)$ points were out of the $95 \%$ LoA.

Figure 2A shows strong correlations between FVC measured by spirometry with $\mathrm{FEV}_{6}$ measured by the handheld expiratory flowmeter in total population $\left(r_{1}=0.835\right.$, $\mathrm{P}<0.001)$, non-COPD group $\left(r_{2}=0.865, \mathrm{P}<0.001\right)$ and COPD group $\left(r_{3}=0.807, \mathrm{P}<0.001\right)$. Statistical difference was detected between non-COPD group and COPD group $(z=2.668, \mathrm{P}=0.008)$. Figure $2 \mathrm{~B}$ shows strong relationships between FVC measured by spirometry and $\mathrm{FEV}_{6}$ measured by the handheld expiratory flowmeter in groups of GOLD stage I $\left(r_{\mathrm{I}}=0.737, \mathrm{P}<0.001\right)$, stage II $\left(r_{\mathrm{II}}=0.724, \mathrm{P}<0.001\right)$, stage III $\left(r_{\mathrm{III}}=0.574, \mathrm{P}=0.0014\right)$, but no significant correlation was found in GOLD stage IV group $\left(\mathrm{r}_{\mathrm{IV}}=0.615\right.$, $\mathrm{P}=0.269)$. No significant difference was found among groups $\left(r_{\mathrm{I}}\right.$ Vs $r_{\text {II }}: z=0.187, \mathrm{P}=0.851 ; r_{\mathrm{I}}$ Vs $\mathrm{r}_{\text {III }}: z=1.301, \mathrm{P}=0.193 ; r_{\text {II }}$ VS $\left.r_{\mathrm{III}}: z=1.161, \mathrm{P}=0.246\right)$. Figure $2 \mathrm{C}$ shows the Bland-Altman graph of FVC by spirometry and $\mathrm{FEV}_{6}$ by the handheld expiratory flowmeter. LoA was $0.514-1.297 \mathrm{~L}$, and $5.2 \%$ (77/1487) points were out of the $95 \%$ LoA.

Figure $3 \mathrm{~A}$ shows the relationship between $\mathrm{FEV}_{1} / \mathrm{FVC}$ measured by spirometry and $\mathrm{FEV}_{1} / \mathrm{FEV}_{6}$ measured by the handheld expiratory flowmeter in total group $\left(r_{1}=0.647\right.$, $\mathrm{P}<0.001)$, non-COPD group $\left(r_{2}=0.343, \quad \mathrm{P}<0.001\right)$ and COPD group $\left(r_{3}=0.686, \mathrm{P}<0.001\right)$. Figure $3 \mathrm{~B}$ shows the relationship between $\mathrm{FEV}_{1} / \mathrm{FVC}$ measured by spirometry and $\mathrm{FEV}_{6} / \mathrm{FVC}$ measured by the handheld expiratory flowmeter in groups of GOLD stage I $\left(r_{\mathrm{I}}=0.197, \mathrm{P}<0.044\right)$, stage II $\left(r_{\text {II }}=0.641, \mathrm{P}<0.001\right)$, stage III $\left(r_{\text {III }}=0.715, \mathrm{P}<0.001\right)$ and stage IV $\left(r_{\mathrm{IV}}=0.784, \mathrm{P}=0.117\right)$. Figure $3 \mathrm{C}$ is the BlandAltman graph of FVC by spirometry and $\mathrm{FEV}_{6}$ by the handheld expiratory flowmeter and the $95 \% \mathrm{LoA}$ is -20.944 to 12.822 .

Table 2 presents the sensitivity, specificity, positive predictive value (PPV), negative predictive value (NPV) and positive likelihood ratio $(\mathrm{LR}+)$ at different cut-off points of $\mathrm{FEV}_{1} / \mathrm{FEV}_{6}$ ratios. The sensitivity was $41.9 \%$, and specificity was $97.9 \%$ with an $\mathrm{FEV} / \mathrm{FEV}_{6}$ ratio $\leq 0.70$, respectively, $77.7 \%$ and $80.0 \%$ with the ratio $\leq 0.80$.

ROC curve was used to determine the best corresponding cut-off for $\mathrm{FEV}_{1} / \mathrm{FEV}_{6}$ (Figure 4A). When the $\mathrm{FEV}_{1} /$ $\mathrm{FEV}_{6}$ cut-off value of was 0.77 , the area under the receiver operator characteristic curve (AUC) was 0.86 (95\% CI: $0.83-0.89)$ and the sensitivity $(71.2 \%)$ and specificity (89.8\%) was greatest. Table 2 shows AUC, sensitivity, specificity, positive predictive value (PPV), negative predictive value (NPV) and positive likelihood ratio (LR+) at different cut-off points of $\mathrm{FEV}_{1} / \mathrm{FEV}_{6}$ ratios.

Figure $4 \mathrm{~B}$ shows ROC curves of $\mathrm{FEV}_{1} / \mathrm{FEV}_{6}$ measured by the handheld expiratory flowmeter to identify airflow obstruction in the symptoms group and asymptomatic 

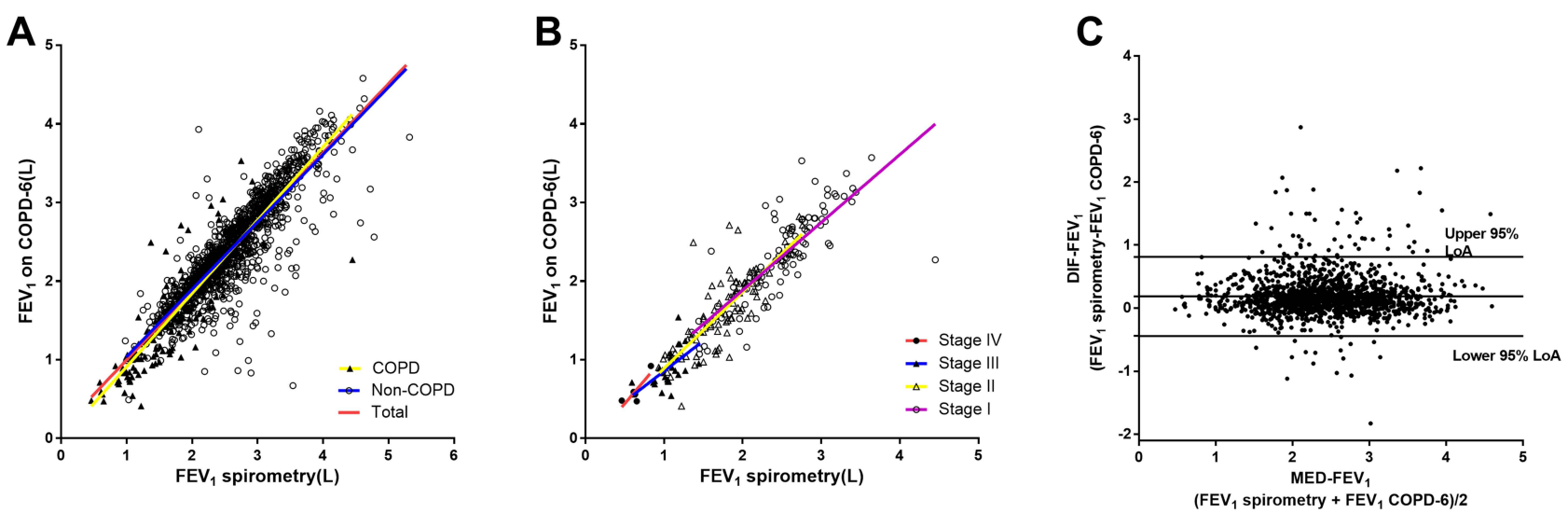

Figure I Correlation of FEV , measured by the conventional spirometry with FEV , measured by the handheld expiratory flowmeter. (A) Relationship between FEV measured by spirometry and FEV , measured by the handheld expiratory flowmeter in total group $\left(r_{1}=0.889, \mathrm{P}<0.00 \mathrm{I}\right)$, non-COPD group $\left(r_{2}=0.869, \mathrm{P}<0.00 \mathrm{I}\right)$ and $\mathrm{COPD}$ group $\left(r_{3}=0.907, \mathrm{P}<0.00 \mathrm{I}\right)$. (B) Relationship between $\mathrm{FEV}$, measured by spirometry and the handheld expiratory flowmeter in the groups of GOLD stage I $\left(r_{1}=0.810\right.$, $\mathrm{P}<0.00 \mathrm{I})$, stage II $\left(r_{\mathrm{II}}=0.802, \mathrm{P}<0.00 \mathrm{I}\right)$, stage III $\left(r_{\mathrm{III}}=0.637, \mathrm{P}<0.00 \mathrm{I}\right)$ and stage IV $\left(r_{\mathrm{IV}}=0.844, \mathrm{P}<0.00 \mathrm{I}\right)$. (C) Bland-Altman graph of FEV measured by spirometry and the handheld expiratory flowmeter. $4.5 \%$ (67/I487) plots were out of the $95 \%$ LoA $(-0.445$ to $0.816 \mathrm{~L})$.
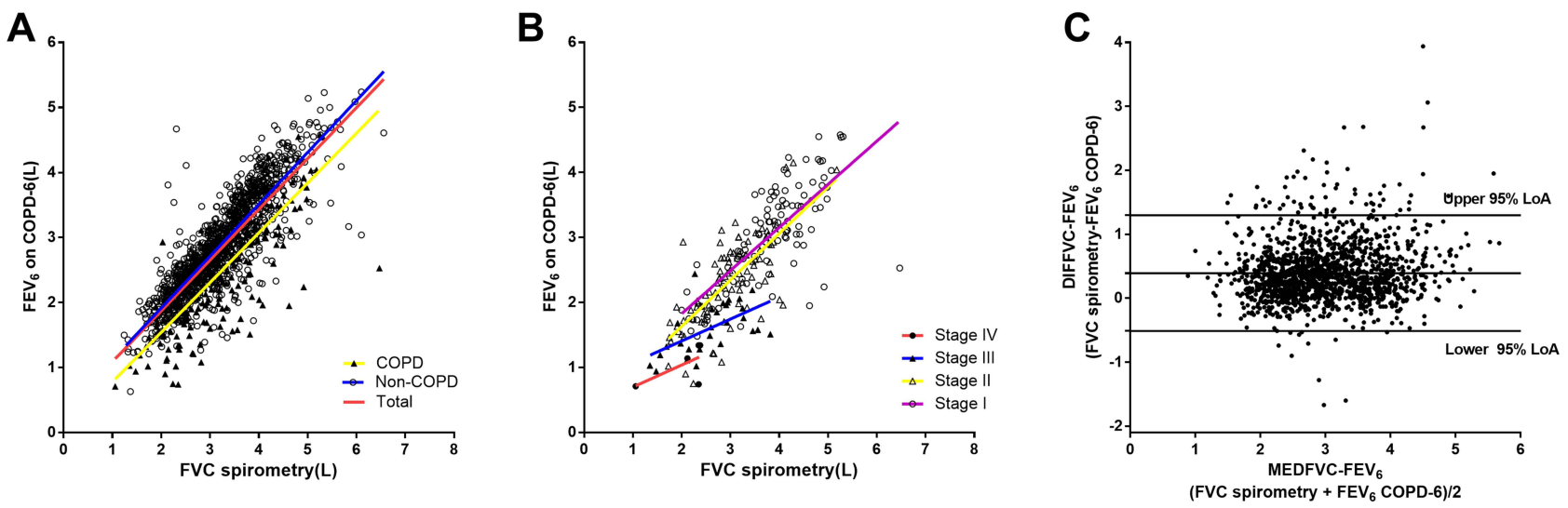

Figure 2 Correlation of FVC measured by the conventional spirometry with $\mathrm{FEV}_{6}$ measured by the handheld expiratory flowmeter. (A) Relationship between FVC measured by spirometry and $\mathrm{FEV}_{6}$ measured by the handheld expiratory flowmeter in total group $\left(r_{1}=0.835, \mathrm{P}<0.00 \mathrm{I}\right)$, non-COPD group $\left(r_{2}=0.865, \mathrm{P}<0.00 \mathrm{I}\right)$ and $\mathrm{COPD}$ group $\left(r_{3}=0.807, P<0.00 I\right)$. (B) Relationship between FVC measured by spirometry and $\mathrm{FEV}_{6}$ measured by the handheld expiratory flowmeter in groups of GOLD stage I $\left(r_{1}=0.737, \mathrm{P}<0.00 \mathrm{I}\right)$, stage II $\left(r_{I I}=0.724, \mathrm{P}<0.00 \mathrm{I}\right)$, stage III $\left(r_{I I I}=0.574, \mathrm{P}=0.00 \mathrm{I} 4\right)$ and stage IV $\left(r_{I_{\mathrm{V}}}=0.6 \mathrm{I}, \mathrm{P}=0.269\right)$. (C) Bland-Altman graph of FVC by spirometry and $\mathrm{FEV} \mathrm{V}_{6}$ by the handheld expiratory flowmeter. 5.2\% (77// 487) plots were out of the 95\%LoA(0.5/4-1.297L).

patients. AUC were 0.87 (95\% CI: $0.82-0.916)$ and 0.84 (95\% CI: $0.802-0.884)$, no significant difference $(z=0.789$, $\mathrm{P}=0.425)$ was observed between two groups. The AUC of $\mathrm{FEV}_{1} / \mathrm{FEV}_{6}$ that used to identify airflow obstruction in the smoker group (including current smokers and ex-smokers) and the never-smokers were 0.86 (95\% CI: 0.82 to 0.90$)$ and 0.84 (95\% CI: 0.79 to 0.89 ), respectively. No significant difference was observed $(z=0.651, \mathrm{P}=0.515)$ (Figure $4 \mathrm{C}$ ).

\section{Discussion}

This is the first study to confirm the validity of a handheld expiratory device for COPD screening for primary care settings in China. We also came out with result that the appropriate cut-off value for $\mathrm{FEV}_{1} / \mathrm{FEV}_{6}$ to determine airflow limitation was 0.77 in Chinese primary care settings, including both rural and urban area.

It has already been demonstrated that $\mathrm{FEV}_{6}$ is a reliable alternative for FVC to detect airway obstruction and restriction. ${ }^{20}$ There are two types of handheld tools made in UK and Ireland for measuring $\mathrm{FEV}_{6}$ and $\mathrm{FEV}_{1} /$ $\mathrm{FEV}_{6}$. Previous studies have demonstrated that these devices could be useful in detecting pulmonary obstructive pathologies. ${ }^{23-28,32}$ However, the best cut-off point to use for defining airflow obstruction remained uncertain. 

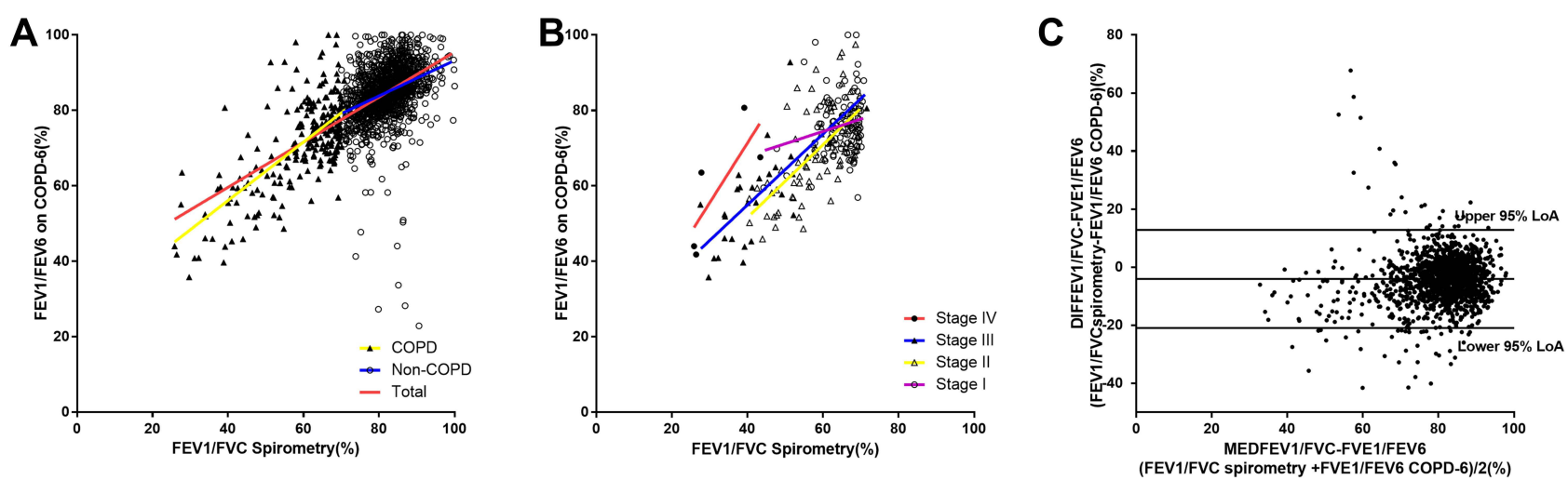

Figure 3 Correlation of FEVI/FVC measured by the conventional spirometry with FEVI/FEV 6 measured by the handheld expiratory flowmeter. (A) Relationship between FEVI/FVC measured by spirometry and FEVI/FEV 6 measured by the handheld expiratory flowmeter in total group $\left(r_{1}=0.647, \mathrm{P}<0.00 \mathrm{I}\right)$, non-COPD group $\left(r_{2}=0.343\right.$, $\mathrm{P}<0.00 \mathrm{I})$ and COPD group $\left(r_{3}=0.686, \mathrm{P}<0.00 \mathrm{I}\right)$. (B) Relationship between FEVI/FVC measured by spirometry and $\mathrm{FEV} / \mathrm{FVC}$ measured by the handheld expiratory flowmeter in groups of GOLD stage I $\left(r_{I}=0.197, \mathrm{P}<0.044\right)$, stage II $\left(r_{I I}=0.64 I, \mathrm{P}<0.00 \mathrm{I}\right)$, stage III $\left(r_{I I I}=0.7 I 5, \mathrm{P}<0.00 \mathrm{I}\right)$ and stage IV $\left(r_{\mathrm{IV}}=0.784\right.$, P $=0.1 \mathrm{I}$ ) $)$ (C) Bland-Altman graph of FVC by spirometry and $\mathrm{FEV}_{6}$ by the handheld expiratory flowmeter.

Vandevoorde et $\mathrm{al}^{33}$ and Melbye et $\mathrm{al}^{34}$ reported that $\mathrm{FEV}_{1} / \mathrm{FEV}_{6}<70-73 \%$ can be used as a valid alternative to $\mathrm{FEV}_{1} / \mathrm{FVC}<70 \%$ for the detection of obstruction using conventional spirometers. Rosa reported that the best cutoff point for the $\mathrm{FEV}_{1} / \mathrm{FEV}_{6}$ ratio was 0.75 in subjects aged 40 years or over. ${ }^{35}$ However, these studies were performed with conventional spirometers. Since we used the handheld spirometer, we cannot blindly adapt these values to our study directly.

In our study, we use $\mathrm{FEV}_{1} / \mathrm{FVC}<70 \%$ as the "gold standard" to detect airflow obstruction. The AUC for $\mathrm{FEV}_{1} / \mathrm{FEV}_{6}$ to identify airflow limitation was 0.857 . The best cut-off point for $\mathrm{FEV}_{1} / \mathrm{FEV}_{6}$ was 0.77 with a sensitivity of $71.2 \%$ and specificity of $89.8 \%$. Besides, almost all of the discordant cases were close to the cut-off

value. Our results in line with a previous study, which determined $73 \%$ as the cut-off value with greatest sensitivity and specificity. ${ }^{27}$ The latest study from the United Kingdom also supports our result with closely cutoff (eg, $78 \%)^{36}$

Table 2 The Measures on Sensitivity and Specificity at Different Cut-Off Points of $\mathrm{FEV}_{1} / \mathrm{FEV}_{6}$

\begin{tabular}{|l|l|l|l|l|l|}
\hline Cut-Off Point & SE\% & SP\% & PPV\% & NPV\% & LR+ \\
\hline$\leq 0.65$ & 25.8 & 98.8 & 80.8 & 88.0 & 23.2 \\
$\leq 0.70$ & 41.9 & 97.9 & 78.7 & 90.3 & 20.3 \\
$\leq 0.75$ & 60.3 & 93.0 & 60.5 & 92.8 & 8.4 \\
$\leq 0.77$ & 71.2 & 89.8 & 55.8 & 94.5 & 6.9 \\
$\leq 0.80$ & 77.7 & 80.0 & 41.3 & 95.2 & 3.9 \\
\hline
\end{tabular}

Abbreviations: SE, sensitivity; SP, specificity; PPV, positive predictive value; NPV, negative predictive value; $L R+$, positive likelihood ratio.
Several seasons led to heterogeneity in studies: methodological measures, different prevalence of airway limitation and the cut-off points used to define airflow obstruction. Previous results of multiple meta-regression presented that the prevalence of airway limitation may have an effect on diagnostic-odds ratio. ${ }^{21}$ According to a previous study, sensitivity and specificity were dependent on the prevalence of moderate-to-severe airway obstruction. Low prevalence of severe airway obstruction may reduce the sensitivity of $\mathrm{FEV}_{6}$, and low prevalence of mild airway obstruction reduced the specificity of $\mathrm{FEV}_{6} \cdot{ }^{37}$ In our study, subjects were randomly selected and representative of the real world. Subjects included smokers and non-smokers, rural and urban residents, previous diagnosed and never diagnosed COPD patients. In this study,

the prevalence of obstruction was $15.3 \%(229 / 1487)$. The best cut-off point for $\mathrm{FEV}_{1} / \mathrm{FEV}_{6}$ was 0.77 with a sensitivity of $71.2 \%$ and specificity of $89.8 \%$. In previous study (population aged 45-85 years and with smoking history of $>15$ pack-years), sensitivity and specificity were $79.2 \%$ and $80.3 \%$ when cut-off value was set as $73 \% .{ }^{27}$ Despite the inconstant result of cut-off point of $\mathrm{FEV}_{1} / \mathrm{FEV}_{6}$, our findings show that the handheld expiratory flowmeter was effective in detecting previously undiagnosed COPD. In comparison to having no diagnosis or a delayed diagnosis without the screening tool, the risk of false positives and negatives for portable spirometers have been accepted by several studies. ${ }^{36,38,39}$ Aimed to provide an evidence for COPD screening in the primary care setting, our program recruited residents aged $\geq 40$ years and did not consider respiratory symptoms, smoking 

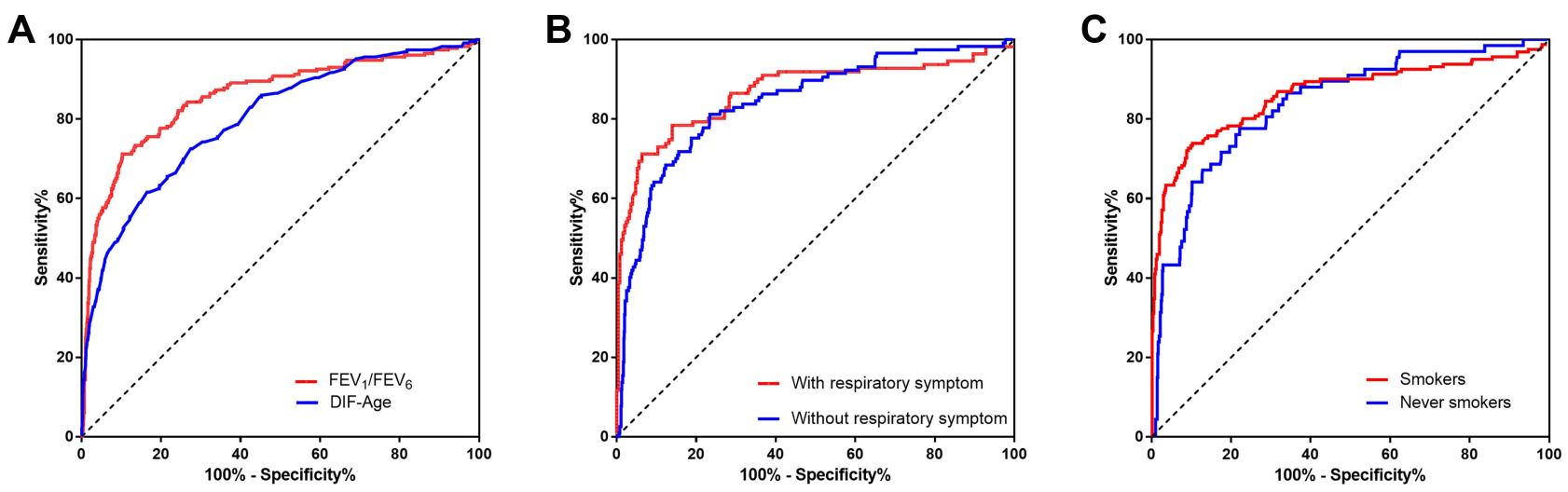

Figure 4 Area under ROC curves for $\mathrm{FEV}_{1} / \mathrm{FEV}_{6}$ measured by the handheld expiratory flowmeter. (A) FEV $/ \mathrm{FEV}_{6}$ by the handheld expiratory flowmeter and DIF-Age("lung age" by the handheld expiratory flowmeter-actual age) to identify airflow obstruction.(B) $\mathrm{FEV}_{1} / \mathrm{FEV}_{6}$ by the handheld expiratory flowmeter to identify airflow obstruction in the population with respiratory symptoms and the population without respiratory symptom. (C) $\mathrm{FEV}_{1} / \mathrm{FEV}_{6}$ by the handheld expiratory flowmeter to identify airflow obstruction in the smokers (including current smokers and ex-smokers) and never-smokers. Using post-bronchodilators FEV $/$ /FVC < $70 \%$ as a "gold standard" for determination of airflow obstruction.

history, and history of chronic respiratory diseases as inclusion criteria. Compared with previous studies, ${ }^{36,38,40}$ there are the two characteristics of our study population. First, the incidence of COPD in this study is $15.4 \%$, which is consistent with the data of the latest large-scale epidemiological survey in China $(13.6 \%$ in people aged 40 years or older). Therefore, subjects in our study are more reflective of the real world. Secondary, $52.3 \%$ of COPD patients in this study were asymptomatic (118/229). Previous studies recruited people at high risk of COPD who could not reflect the characteristics of residents in communities. These two major factors determine a slightly lower sensitivity (ie, 71\%) when the optimal cut-off point is used. Nevertheless, the portable spirometer was still able to detect fundamental COPD patients in early stage without respiratory symptoms, which provides the possibility for early diagnosis and treatment for these patients. In addition, the specificity of the portable spirometer was $89.8 \%$ which could avoid the need for more people to enter the next step of laboratory examination. It should be emphasized that COPD-6 is only used as a screening tool but not a diagnosis approach, and people who are positive for COPD-6 screening or have other abnormal measures (ie, FEV1/pre $<0.8)^{41}$ will be recommended for further diagnosis with a conventional spirometry. Therefore, portable spirometers could be used as a tool for COPD screening in Chinese primary care settings.

Furthermore, similar AUC values were obtained in the symptomatic population $(\mathrm{AUC}=0.87)$ and asymptomatic population $(\mathrm{AUC}=0.84)$. No significant difference was observed between smoking group (including smokers and ex-smokers $)(\mathrm{AUC}=0.86)$ and non-smokers $(\mathrm{AUC}=0.84)$. The results remind us that the handheld expiratory flowmeter was effective in detecting airflow limitation for population with diverse characteristics, especially in non-smokers and asymptomatic patients.

To the best of our knowledge, handheld spirometric measurements are not identical to conventional spirometry. The most limitation of this approach was handheld spirometric measurements may not be appropriate for determining the grade of airflow limitation. We assessed the correlation of several measures by the handheld expiratory flowmeter and conventional spirometry at different stages of COPD. No significant correlations were observed between FVC measured by spirometry and $\mathrm{FEV}_{6}$ measured by the handheld expiratory flowmeter in GOLD stage IV. FEV 1 FVC measured by spirometry was also not correlated with $\mathrm{FEV}_{1} / \mathrm{FEV}_{6}$ measured by the handheld expiratory flowmeter in GOLD stage IV.

These phenomena indicated the fact that the handheld expiratory flowmeter may not be appropriate for determining the grade of airflow limitation.

There are several potential reasons for differences and inconsistency mentioned above: 1) $\mathrm{FEV}_{1} / \mathrm{FVC}$ and $\mathrm{FVC}$ are more dependent on the FET (forced expiratory time) than $\mathrm{FEV}_{1} / \mathrm{FEV}_{6}$ and $\mathrm{FEV}_{6}{ }^{42}$; 2) instead of measuring the whole FVC, the handheld expiratory flowmeter testing stops measuring after $6 \mathrm{~s}$ and results in the risk of overstating $\mathrm{FEV}_{1}$ / $\mathrm{FEV}_{6}$ ratio; 3) the handheld expiratory flowmeter does not provide graph analysis of the volume/time or flow/volume curves that are essential (especially the later ones) in quality control; 4) in this study, the handheld expiratory flowmeter 
were performed before the use of bronchodilation, and the conventional spirometry were adapted after the process of post-bronchodilation; 5) in our study, only five patients were GOLD stage IV, which might cause statistical bias.

However, limitations mentioned above are irrelevant for the COPD screening in primary care settings. Utilization of the handheld expiratory flowmeter was aimed to reduce misdiagnosis rate and avoid the waste of medical resources at the same time. Our study, including the handheld expiratory flowmeter and its cutoff value, can be widely recommended for the practice of COPD screening in Chinese communities.

\section{Conclusions}

The handheld expiratory flowmeter could be used as a prescreening device in early diagnosis of COPD in Chinese primary care settings. Furthermore, it should be noted that the cut-off value for $\mathrm{FEV}_{1} / \mathrm{FEV}_{6}$ to determine airflow limitation was 0.77 .

\section{Acknowledgments}

This study was supported by the National Key R\&D Program of China, Ministry of Science and Technology of China (2016YFC1304100), the National Natural Science Foundation of China $(81970045,81570035)$, the special fund for preventing and controlling the COVID-19, Guangdong, China (2020B1111330001), and Provincial Innovation and Research Team Project of Guangdong Pearl River Talents Program, China (2017BT01S155). However, the aforementioned study funders had no influence on the process of study.

\section{Disclosure}

The authors declare that they have no conflicts of interest for this work.

\section{References}

1. Mathers CD, Loncar D. Projections of global mortality and burden of disease from 2002 to 2030. PLoS Med. 2006;3(11):e442. doi:10.1371/ journal.pmed.0030442

2. World Health Organisation. The Global Burden of Disease: 2004 Update. 2008.

3. Soriano JB, Abajobir AA, Abate KH; Collaborators GBDCRD. Global, regional, and national deaths, prevalence, disability-adjusted life years, and years lived with disability for chronic obstructive pulmonary disease and asthma, 1990-2015: a systematic analysis for the Global Burden of Disease Study 2015. Lancet Respir Med. 2017;5 (9):691-706. doi:10.1016/S2213-2600(17)30293-X

4. Lange P, Halpin DM, O'Donnell DE, MacNee W. Diagnosis, assessment, and phenotyping of COPD: beyond FEV(1). Int $J$ Chron Obstruct Pulmon Dis. 2016;11:3-12. doi:10.2147/COPD.S85976
5. Singh D, Agusti A, Anzueto A, et al. Global strategy for the diagnosis, management, and prevention of chronic obstructive lung disease: the GOLD science committee report 2019. Eur Respir J. 2019.

6. Celli BR, MacNee W. Standards for the diagnosis and treatment of patients with COPD: a summary of the ATS/ERS position paper. Eur Respir J. 2004;23(6):932-946. doi:10.1183/09031936.04.00014304

7. Soriano JB, Zielinski J, Price D. Screening for and early detection of chronic obstructive pulmonary disease. Lancet. 2009;374 (9691):721-732. doi:10.1016/S0140-6736(09)61290-3

8. Bednarek M, Maciejewski J, Wozniak M, Kuca P, Zielinski J. Prevalence, severity and underdiagnosis of COPD in the primary care setting. Thorax. 2008;63(5):402-407. doi:10.1136/ thx.2007.085456

9. Freeman D, Price D. ABC of chronic obstructive pulmonary disease. Primary care and palliative care. BMJ. 2006;333(7560):188-190. doi:10.1136/bmj.333.7560.188

10. Labonté LE, Tan WC, Li PZ, et al. Undiagnosed chronic obstructive pulmonary disease contributes to the burden of health care use. Data from the CanCOLD Study. Am J Respir Crit Care Med. 2016;194 (3):285-298. doi:10.1164/rccm.201509-1795OC

11. Han MK, Kim MG, Mardon R, et al. Spirometry utilization for COPD: how do we measure up? Chest. 2007;132(2):403-409. doi: $10.1378 /$ chest.06-2846

12. Johns DP, Burton D, Walters JA, Wood-Baker R. National survey of spirometer ownership and usage in general practice in Australia. Respirology. 2006;11(3):292-298. doi:10.1111/j.14401843.2006.00851.x

13. Leuppi JD, Miedinger D, Chhajed PN, et al. Quality of spirometry in primary care for case finding of airway obstruction in smokers. Respiration. 2010;79(6):469-474. doi:10.1159/000243162

14. Derom E, van Weel C, Liistro G, et al. Primary care spirometry. Eur Respir J. 2008;31(1):197-203. doi:10.1183/09031936.00066607

15. Qaseem A, Snow V, Shekelle P, et al. Diagnosis and management of stable chronic obstructive pulmonary disease: a clinical practice guideline from the American College of Physicians. Ann Intern Med. 2007;147(9):633-638. doi:10.7326/0003-4819-1479-200711060-00008

16. Calonge N, Petitti DB, DeWitt TG, et al. Screening for chronic obstructive pulmonary disease using spirometry: U.S. preventive services task force recommendation statement. Ann Intern Med. 2008;148(7):529-534. doi:10.7326/0003-4819-148-7-20080401000212

17. Prats E, Tejero E, Pardo P, et al. Prognostic value of the six-second spirometry in patients with chronic obstructive pulmonary disease: a Cohort Study. PLoS One. 2015;10(10):e0140855. doi:10.1371/journal.pone. 0140855

18. Chung KS, Jung JY, Park MS, et al. Cut-off value of FEV1/FEV6 as a surrogate for FEV1/FVC for detecting airway obstruction in a Korean population. Int $J$ Chron Obstruct Pulmon Dis. 2016;11:1957-1963. doi:10.2147/COPD.S113568

19. Lundgren FL, Cabral MM, Climaco DC, de Macedo LG, Coelho MA, Dias AL. Determination of the efficacy of FEV6 as a surrogate for FVC in the diagnostic screening for chronic obstructive pulmonary disease through the comparison of FEV1/FVC and FEV1/FEV6 ratios. $J$ Bras Pneumol. 2007;33(2):148-151. doi:10.1590/S1806-37132007000200008

20. Vandevoorde J, Verbanck S, Schuermans D, Kartounian J, Vincken W. FEV1/FEV6 and FEV6 as an alternative for FEV1/ $\mathrm{FVC}$ and FVC in the spirometric detection of airway obstruction and restriction. Chest. 2005;127(5):1560-1564. doi:10.1378/ chest.127.5.1560

21. Vollmer WM, Gislason T, Burney P, et al. Comparison of spirometry criteria for the diagnosis of COPD: results from the BOLD Study. Eur Respir J. 2009;34(3):588-597. doi:10.1183/ 09031936.00164608 
22. Jing JY, Huang TC, Cui W, Xu F, Shen HH. Should FEV1/FEV6 replace FEV1/FVC ratio to detect airway obstruction? A metaanalysis. Chest. 2009;135(4):991-998. doi:10.1378/chest.080723

23. Frith P, Crockett A, Beilby J, et al. Simplified COPD screening: validation of the PiKo-6(R) in primary care. Prim Care Respir J. 2011;20(2):190-198, 192. doi:10.4104/pcrj.2011.00040

24. Sichletidis L, Spyratos D, Papaioannou M, et al. A combination of the IPAG questionnaire and PiKo-6(R) flow meter is a valuable screening tool for COPD in the primary care setting. Prim Care Respir J. 2011;20(2):184-189, 181. doi:10.4104/pcrj.2011.00038

25. Wada H, Nakano Y, Nagao $T$, et al. Detection and prevalence of chronic obstructive pulmonary disease in a cardiovascular clinic: evaluation using a hand held FEV/FEV meter and questionnaire. Respirology. 2010;15(8):1252-1258. doi:10.1111/j.14401843.2010.01854.x

26. Represas RC, Botana RM, Leiro FV, Gonzalez SA, Del CPV, Fernandez-Villar A. [Assessment of the portable COPD-6 device for detecting obstructive airway diseases]. Arch Bronconeumol. 2010;46(8):426-432. Spanish. doi:10.1016/S1579-2129(10)70101-4

27. Thorn J, Tilling B, Lisspers K, Jorgensen L, Stenling A, Stratelis G. Improved prediction of COPD in at-risk patients using lung function pre-screening in primary care: a real-life study and cost-effectiveness analysis. Prim Care Respir J. 2012;21(2):159-166. doi:10.4104/ pcrj.2011.00104

28. Miravitlles M, Llor C, Calvo E, Diaz S, Diaz-Cuervo H, GonzalezRojas N. [Validation of the Spanish version of the chronic obstructive pulmonary disease-population screener (COPD-PS). Its usefulness and that of $\mathrm{FEV}(1) / \mathrm{FEV}(6)$ for the diagnosis of COPD]. Med Clin (Barc). 2011;139(12):522-530. Italian. doi:10.1016/j. medcli.2011.06.022

29. Nishimura K, Nakayasu K, Kobayashi A, Mitsuma S. Case identification of subjects with airflow limitations using the handheld spirometer "Hi-Checker": comparison against an electronic desktop spirometer. COPD. 2011;8(6):450-455. doi:10.3109/ 15412555.2011.626817

30. Miller MR, Hankinson J, Brusasco V, et al. Standardisation of spirometry. Eur Respir J. 2005;26(2):319-338. doi:10.1183/ 09031936.05.00034805

31. Enright PL, Studnicka M, Zielinski J. Spirometry to detect and manage chronic obstructive pulmonary disease and asthma in the primary care setting. Eur Respir Monogr. 2005:1-14.

32. Toda R, Hoshino T, Kawayama T, et al. Validation of "lung age" measured by spirometry and handy electronic FEV1/FEV6 meter in pulmonary diseases. Intern Med. 2009;48(7):513-521. doi:10.2169/ internalmedicine.48.1781
33. Vandevoorde J, Verbanck S, Schuermans D, Kartounian J, Vincken W. Obstructive and restrictive spirometric patterns: fixed cut-offs for FEV1/FEV6 and FEV6. Eur Respir J. 2006;27 (2):378-383. doi:10.1183/09031936.06.00036005

34. Melbye H, Medbo A, Crockett A. The FEV1/FEV6 ratio is a good substitute for the FEV1/FVC ratio in the elderly. Prim Care Respir J. 2006;15(5):294-298. doi:10.1016/j.pcrj.2006.07.002

35. Rosa FW, Perez-Padilla R, Camelier A, Nascimento OA, Menezes AM, Jardim JR. Efficacy of the FEV1/FEV6 ratio compared to the FEV1/FVC ratio for the diagnosis of airway obstruction in subjects aged 40 years or over. Braz J Med Biol Res. 2007;40 (12):1615-1621. doi:10.1590/S0100-879X2006005000182

36. Dickens AP, Fitzmaurice DA, Adab P, et al. Accuracy of Vitalograph lung monitor as a screening test for COPD in primary care. NPJ Prim Care Respir Med. 2020;30(1). doi:10.1038/s41533-019-0158-2

37. Lamprecht B, Schirnhofer L, Tiefenbacher F, et al. Six-second spirometry for detection of airway obstruction: a population-based study in Austria. Am J Respir Crit Care Med. 2007;176(5):460-464. doi:10.1164/rccm.200702-337OC

38. Ching SM, Pang YK, Price D, et al. Detection of airflow limitation using a handheld spirometer in a primary care setting. Respirology. 2014;19(5):689-693. doi:10.1111/resp.12291

39. Sami R, Omidi A, Sadegh R. Validity and reliability of COPD-6 device for detecting chronic obstructive pulmonary disease in high-risk individuals. Tanaffos. 2020;19(3):201-207.

40. Gil-Guillén V, Orozco-Beltrán D, Carratala Munuera CV, et al. FUMEPOC: early detection of chronic obstructive pulmonary disease in smokers. BMC Public Health. 2011;11(1):413. doi:10.1186/14712458-11-413

41. Kjeldgaard P, Lykkegaard J, Spillemose H, Ulrik CS. Multicenter study of the COPD-6 screening device: feasible for early detection of chronic obstructive pulmonary disease in primary care? Int J Chron Obstruct Pulmon Dis. 2017;12:2323-2331. doi:10.2147/COPD. $\mathrm{S} 136244$

42. Perez-Padilla R, Wehrmeister FC, Celli BR, et al. Reliability of FEV1/FEV6 to diagnose airflow obstruction compared with FEV1/ FVC: the PLATINO longitudinal study. PLoS One. 2013;8(8): e67960. doi:10.1371/journal.pone.0067960

\section{Publish your work in this journal}

The International Journal of COPD is an international, peer-reviewed journal of therapeutics and pharmacology focusing on concise rapid reporting of clinical studies and reviews in COPD. Special focus is given to the pathophysiological processes underlying the disease, intervention programs, patient focused education, and self management protocols. This journal is indexed on PubMed Central, MedLine and CAS. The manuscript management system is completely online and includes a very quick and fair peer-review system, which is all easy to use. Visit http://www.dovepress.com/testimonials.php to read real quotes from published authors 